\title{
Alcohol industry sponsorship and hazardous drinking in UK university students who play
} sport

Kerry S. O’Brien ${ }^{1,2^{*}}$, Jason Ferris ${ }^{3}$, Ian Greenlees ${ }^{4}$, Sophia Jowett ${ }^{5}$, Daniel Rhind ${ }^{6}$, Kypros Kypri $^{7}$, Penny Cook ${ }^{8}$.

Behavioural Studies, Monash University, Australia ${ }^{1}$; School of Psychological Sciences, University of Manchester, $\mathrm{UK}^{2}$; Institute for Social Science Research, University of Queensland, Australia ${ }^{3}$; Department of Sport and Exercise Sciences, University of Chichester, UK ${ }^{4}$; School of Sport, Exercise and Health Sciences, Loughborough University, $\mathrm{UK}^{5}$; Brunel Centre for Sport, Health and Wellbeing, Brunel University, UK ${ }^{6}$; School of Medicine \& Public Health, University of Newcastle, Australia ${ }^{7}$; School of Health Sciences, Salford University, $\mathrm{UK}^{8}$;

Declaration of Interest: The research was supported by grant funding from Alcohol Research UK. KOB was also supported by funding from the Australian Research Council, VicHealth, and the Australian National Preventive Health Agency. There are no conflicts of interest to declare.

Running Head: Alcohol sponsorship of sport

Key Words: Sport, Athletes, Drinking, Hazardous, Alcohol Sponsorship.

* Author to whom correspondence should be addressed at: School of Political and Social Sciences, Monash University, VIC, Australia.

E-mail: kerrykez@gmail.com 


\begin{abstract}
Aim: To examine whether receipt of alcohol industry sponsorship is associated with problematic drinking in UK university students who play sport.

Methods: University students $(\mathrm{n}=2450)$ participating in sports were invited to complete a pen-andpaper questionnaire by research staff approaching them at sporting facilities and university settings. Respondents were asked whether they personally, their team, and/or club were currently in receipt of sponsorship (e.g., money, free or subsidised travel, or sporting products), from an alcohol-related industry (e.g., bars, liquor stores, wholesalers), and whether they had solicited the sponsorship. Drinking was assessed using the Alcohol Use Disorders Identification Test (AUDIT).
\end{abstract}

Findings: Questionnaires were completed by 2048 of those approached (response rate $=83 \%$ ). Alcohol industry sponsorship was reported by $36 \%$ of the sample. After accounting for confounders (age, gender, disposable income, and location) in multivariable models, receipt of alcohol sponsorship at a team (adjusted $\left.\beta_{\mathrm{adj}}=.41, \mathrm{p}=.013\right), \operatorname{club}\left(\beta_{\mathrm{adj}}=.73, \mathrm{p}=.017\right)$, team and $\operatorname{club}\left(\beta_{\mathrm{adj}}=.79\right.$, $\mathrm{p}=0.002)$, and combinations of individual and team or club sponsorships $\left(\beta_{\mathrm{adj}}=1.27, \mathrm{p}<0.002\right)$, were each associated with significantly higher AUDIT-Consumption substance scores. Receipt of sponsorship at team and club $(\mathrm{aOR}=2.04 ; 95 \% \mathrm{CI}: 1.04-3.99)$ and combinations of individual and team or club sponsorships (aOR=4.12; 95\% CI: 1.29-13.15) were each associated with increased odds of being classified a hazardous drinker (AUDIT score $\geq 8$ ). Receipt of alcohøl spensorship at at elub $(\mathrm{aOR}=1.66 ; 95 \% \mathrm{CI}: 1.20-2.30)$, team and club $(\mathrm{aOR}=1.57 ; 95 \% \mathrm{CI} 1.23-1.99)$, or combinations of individual and team or club spensorships (aOR=4.04; 95\% CI 1.58-10.3) were associated with increased risk of possible alcohol dependence (AUDIT score $\geq 16$ ). Respondents who sought out sponsorship were not at increased risk compared respondents who had, or whose teams or clubs had, been approached by the alcohol industry.

Conclusions: Receipt of alcohol industry sponsorship is associated with more problematic drinking behaviour in UK university students who play sport. Policy to reduce or cease such sponsorship should be considered. 


\section{Introduction}

Hazardous consumption of alcohol is a leading cause of mortality and morbidity in middle and high income countries [1], ranked above illicit drug use in terms of social, health, and financial costs [2]. In the UK alone, the cost of hazardous drinking is approximately $£ 25$ billion per year [3]. Hazardous drinking is particularly common in young people and university students [4,5], and even more so in university students who play sport [6-12]. Research from the USA, Australia, and New Zealand, suggests that sportspeople, and especially university students who play sport, drink more

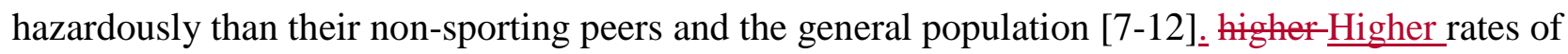
drink-driving, anti-social behaviour, and unprotected sex were also found in university sports participants $[6,7,11]$. Only one published study has examined drinking in UK university sportspeople, finding that hazardous drinking was more prevalent among sportspeople than their non-sporting peers [12]. There has been no research examining whether alcohol industry sponsorship is associated with increased risk of hazardous drinking in the UK or indeed elsewhere in Europe.

A review of the small literature on factors which might explain heavy drinking among sportspeople suggests that using alcohol for team cohesion and coping, and the drinking of peers probably play a role [7], along with specific practices such as drinking with teammates and opponents after matches [13]. There has been a strong interdependence between sport and alcohol industries for several hundred years in the UK. For example, pubs traditionally hosted and funded sport competitions for customer entertainment and gambling. During the industrial revolution many of the world's largest sporting clubs (e.g., Manchester United) were funded or owned by alcohol industries in the UK [14].

Sport continues to be a primary vehicle for the promotion of alcohol, with a large proportion of the alcohol industry's advertising and sponsorship budget spent on sport $[15,16]$. Alcohol industry marketing contributes to problem drinking [17-21]. Systematic reviews of longitudinal studies show that early exposure of young people to alcohol advertising and sponsorship is 
associated with stronger intentions to drink, and later-higher levels of alcohol consumption in later adolescence to early adulthood [20,21]. A ban on alcohol advertising and sponsorship has been called for by peak medical bodies in the UK, Ireland, Australia, and South Africa [22-24], and in the UK House of Commons Health Select Committee Report on Alcohol [25]. The UK government's official response to calls for stronger regulation of alcohol advertising and sponsorship was that more evidence is required [26].

Alcohol industry sponsorship of sport refers not only to payments for event naming and product marketing rights (e.g., "Heineken \& UEFA Champions League Football”), which are in effect advertising, but also to less conspicuous but potentially more harmful direct to user sponsorship [27-29]. This direct sponsorship occurs from grass-roots to elite level sport, encompassing the payment of club fees, provision of uniforms, payment of travel costs, and provision of alcohol at post match functions. In return, sponsored individuals, teams, and clubs are often required to wear the sponsor's logo and to attend and drink at the sponsor's premises [28]. For example, a bar provides a local football team with a cash payment to cover uniform costs. In return the team has that bar's name printed on the jersey and agrees to drink at the bar after games, bringing the opposition team and spectators, friends, and family. In this way the bar attracts new customers and creates a sense of obligation in club members.

A recent multination EU longitudinal study found that children with indirect exposure to sports clubs receiving alcohol sponsorship reported more positive drinking expectancies and had higher odds of having consumed alcohol in the past month [30]. Studies from New Zealand and Australia found that sportspeople in receipt of alcohol industry sponsorship were more likely to be hazardous drinkers $[28,29]$. The previous work was unable account for possible confounders such as disposable income, nor whether participants sought out alcohol sponsorship, to examine the possibility that a predilection for drinking leads to sponsorship and not vice versa. There has been no UK research examining the association between alcohol industry sponsorship of sport and hazardous drinking among sportspeople despite both practices being common [31]. Our aim was to 
examine whether receipt of alcohol industry sponsorship is positively associated with alcohol consumption and hazardous drinking in UK sportspeople.

\section{Methods}

\section{Participants}

To circumvent the possibility that some sporting organisations (e.g., clubs) would deny access to sportspeople thereby biasing findings, we approached participants directly at university playing fields, training facilities, and sport-related teaching venues and classes. The aim was to achieve heterogeneity in the exposure of interest, namely, alcohol sponsorship, rather than to estimate prevalence. Although the prevalence of alcohol industry sponsorship of sportspeople in the UK is unknown, alcohol industry practices and sporting cultures appear similar to those in New Zealand and Australia where $47 \%$ and $30 \%$, respectively, of respondents approached via the same method were currently in receipt of alcohol sponsorship [28,29]. We therefore expected at least $30 \%$ of participants to be in receipt of alcohol industry sponsorship. The primary assumption underlying the inferences we seek to draw are that how participants came into the study would not be systematically related to the association of interest [32], i.e., whether receiving industry funding increases the likelihood of hazardous drinking. The risk of selection bias from this recruitment approach was judged likely to be lower than that arising from non-participation of some sporting bodies who may have considered involvement in the research to create a commercial or reputational risk.

It is also important to note that the participants in this study where not necessarily involved in university sport competitions, which is a common classification in US studies involving National Collegiate Athletic Associations. The university students surveyed here were identified as participants in sport not necessarily run by a university. Given that we cannot know how representative the participants are of the population of sportspeople or even of UK university students engaged in sport, prevalence rates are not estimated. 
Sample size estimate

For multiple regression, the rule of thumb $\mathrm{N}>=(8 / \mathrm{f} 2)+(\mathrm{m}-1)$ gives a sample size of 809 where $\mathrm{m}=$ number of predictors $=10, \mathrm{f} 2=$ effect $\operatorname{size}=0.1$ [33]. To examine relationships between sponsorship type and AUDIT score among those receiving sponsorship, we assumed that $30 \%$ of the sample would receive sponsorship. Accordingly, 450 respondents would be sufficient to detect an $\mathrm{f} 2$ of 0.14 , i.e. a small-moderate effect, equivalent to $\mathrm{R}^{2}=12 \%$.

\section{Measures}

Participants were presented with a short questionnaire assessing demographic details (age, gender, sports played, weekly disposable income, and geographical location), whether respondents had received alcohol industry sponsorship, and the Alcohol Use Disorders Identification Test (AUDIT) which consists of 10 questions with a total score range of 0-40 [34]. Its validity has been thoroughly established with a score of $\geq 8$ indicative of hazardous drinking [35]. The AUDIT consumption subscale (AUDIT-C), consisting of the first three questions, is a measure of alcohol consumption, with a range $0-12$ [34].

Receipt of alcohol industry sponsorship was assessed using an identical item and response format to those described in previous research [28,29]. In summary, participants were asked if they, their team, or their club currently received sponsorship (e.g., money, equipment, travel costs, discounted/free alcohol) from an alcohol industry body (e.g., a bar, hotel, liquor store, or producer). Participants who were uncertain about their team or club sponsorship arrangements were coded as 'no' for receipt of alcohol industry sponsorship. It should be noted that classification error arising from this assumption being incorrect can only bias associations toward the null.

Heavier drinkers may preferentially seek out alcohol industry sponsorship rather than heavier drinking resulting from receipt of alcohol sponsorship, an important issue in making inferences about the likely direction of any association identified [36]. Accordingly, we asked participants who reported receiving alcohol industry sponsorship to report whether they, their team, 
or club, sought out alcohol industry sponsorship or whether they, their team, or club, had been approached by an alcohol industry body offering sponsorship.

\section{Procedure}

Data collection occurred between September 2010 and February 2012, encompassing in-season winter and summer sports (see Table 1). Venues for data collection were identified from university webpage listings and competition schedules posted in newsletters. Most venues were owned or leased by universities, and all were within a 2-mile radius of 10 universities situated in the North West, Midlands, London, and Southern region of England. None of the venues had bars associated with them. Non-team sport venues (e.g., tennis) with small numbers of participants present at any one time were visited up to five times.

Upon arrival at venues, researchers approached the nearest sportsperson and invited them to participate. Following acceptance or rejection of the invitation the data collector approached the next nearest sportsperson for participation, and so on until all potential participants at the venue had been approached. Researchers were on hand to assist with participant queries. Participants were offered a nominal incentive of $£ 2$ for participation, were informed that their participation would remain confidential and that identifying information was not being requested. The questionnaire took approximately 15 minutes to complete. Ethical approval was obtained from the human research ethics committees of the University of Manchester, Loughborough University, Brunel University, and the University of Chichester.

\section{Questions about exposure of interest}

Participants were asked "Do you personally, your team, or club receive sponsorship or support (e.g., financial payments, competition fees, clothing, club pourage rights, other goods) from an alcoholrelated industry (e.g., pub, bar, winery, brewer, distillery, hotel, nightclub)? Responses options for 
each of the following response categories were: Personally: no or yes; Team: no or yes or uncertain; and Club: no or yes or uncertain.

\section{Statistical Analyses}

Drinking outcomes of interest were alcohol consumption, hazardous drinking status, and possible alcohol dependence. The AUDIT-C (henceforth referred to as alcohol consumption) was treated as a continuous variable. Participants with AUDIT scores $\geq 8$ were classified as hazardous drinkers.

Multiple linear regression models adjusting for age, gender, location and disposable income, were used to examine associations between between alcohol sponsorship variables and alcohol consumption scores. Multiple logistic regression models controlling for the same variables were used to estimate associations between sponsorship variables and the two dichotomous outcomes: hazardous drinker and possibly alcohol dependent. In all models clustering within sports was accounted for using the STATA vce command. Due to the large variation in the number of people within different sport types we also bootstrapped the models. We set bootstrapping to 1000 replications to make sure the variance estimators were sufficiently ranked. We used ANOVA to test for sponsorship status differences in age, disposable income, and AUDIT-C scores, and Pearson's Chi Squared tests for gender differences in the proportion of participants classified as hazardous drinkers.

\section{Results}

A sample of 2048 sportspeople (892 females, 44\%) was recruited (response rate $83 \%$ ). Table 2 presents the characteristics of respondents by sponsorship status. Eighty-one participants (4\%) were abstainers. The proportion with hazardous drinking (AUDIT score $\geq 8$ ) was $84 \%$.

\section{Sponsorship}


Thirty-six per cent $(n=575)$ of participants were in receipt of alcohol industry sponsorship. It should be noted that 338 participants (19\%) did not answer questions about disposable income, reducing the number available for analysis to 1658 . We found no association between whether participants indicated their disposable income and AUDIT-C scores (mean difference - 0.04 points, 95\% CI -0.34 to 0.26 ) or sponsorship seeking (difference -0.0003 in proportions, $95 \%$ CI -0.14 to 0.14). Participants who did not answer these questions were less likely to have received sponsorship (difference -0.24 in proportions $95 \%$ CI -0.28 to -0.19 ). The initial examination of the association between alcohol consumption and each of the modelled variables (Table 3) shows that all covariates were significantly associated with alcohol consumption patterns. After adjusting for these covariates, the final model (Table 3) indicates that sportspeople who received alcohol industry sponsorship had significantly higher alcohol consumption than sportspeople who did not $\left(\chi^{2},(1643)=\right.$ 431.17, $P<.0001)$. In particular, those sponsored at the level of team, club, both team and club, or with combinations of personal and team or club sponsorship had higher alcohol consumption scores than sportspeople not sponsored by the alcohol industry.

Table 4 displays results for bivariate and multivariable logistic regression models examining the associations between explanatory variables and the hazardous drinker outcome. All covariates except for gender were associated with hazardous drinking. The overall association between sponsorship type and hazardous drinking was statistically significant $\left(\chi^{2}(4)=35.9, p<0.001\right)$. The risk of hazardous drinking was associated with club sponsorship and with team and club sponsorship. After adjusting for the other variables in Table 3 associations between receiving any sponsorship and being a hazardous drinker $\left(\chi^{2}(4)=11.93, P=0.018\right)$ or possibly alcohol dependent were each statistically significant $\left(\chi^{2}(4)=27.21, P<0.001\right)$.

We also tested the hypothesis that heavier drinking sportspeople may preferentially seek out alcohol industry sponsorship. After adjusting for all other variables in regression models, those seeking out sponsorship did not have significantly greater alcohol consumption than those who were approached by an alcohol industry sponsor ( $\beta_{\text {Adj }} 0.80,95 \%$ CI: 0.52-1.22). Similarly, seeking 
sponsorship was not significantly associated with being a hazardous drinker $(\mathrm{aOR}=1.19,95 \% \mathrm{CI}$ :

$0.62-2.27)$ or being possibly alcohol dependent (aOR=1.56, 95\% CI: 0.68- 3.62). Finally, we explored interaction effects between gender and type of sponsorship for each of the three multivariable models, finding that none was significant (p-values $>0.17$ ).

\section{Discussion}

There had been no previous research examining the association between alcohol industry sponsorship and drinking among sports participants in Europe. After controlling for several confounders (age, gender, disposable income, location) receipt of alcohol industry sponsorship at any level (individual, team, club, or combinations of these) was associated with higher levels of alcohol consumption. Sportspeople in receipt of alcohol industry sponsorship had greater odds of being hazardous drinkers or having possible alcohol dependence. The results are in line with findings from both Australia and New Zealand, which showed an association between receipt of alcohol sponsorship and hazardous drinking in university [29] and community [28] sporting samples. The results of this study build upon previous research by accounting for disposable income which is strongly associated with alcohol consumption in young people [37]; and by studying a greater number and wider distribution of regions than in previous studies.

We also tested whether the association might reflect heavier drinkers seeking out alcohol industry sponsorship, a possibility raised by alcohol industry bodies as an alternative explanation for findings of previous research [38,39]. After controlling for several known confounders, there was no significant difference in drinking outcomes for those who reported seeking alcohol sponsorship versus those being offered sponsorship by the alcohol industry. Although this does rule out the possibility of confounding by unidentified variables, it does suggest that the association between alcohol industry sponsorship and problematic drinking is unlikely to be due to the latter causing the former. 
The primary limitation of the study is the cross-sectional design, which precludes causal attribution. The statistical control of confounders and the test of sponsorship seeking behaviour reduces, but does not eliminate, the possibility that other factors may account for the association between alcohol sponsorship and drinking outcomes. Furthermore, by treating geographical location of respondents as a fixed effect in the analysis the findings may not generalise to other UK locations. Relatedly, because the sample was university students involved in sport, it is uncertain as to whether the associations would generalise to non-students. Notably, however, research in a New Zealand community sample had a similar pattern of results as found here [26].

The measures of exposure are simple statements rather than validated scales. The development of full scales with established reliability and validity may be warranted in future, however, the questions have high face validity and our pilot research preceding previous studies using these items shows that respondents understand the questions and can answer them reliably.

While consistent with findings from other countries [40-42], the high level of problematic drinking in UK university sportspeople is noteworthy regardless of sponsorship status. The AUDIT total score $($ mean=14.4) and proportion of hazardous drinkers $(84 \%)$ in this population group were high compared with estimates of these parameters in a recent study in English university students (mean=9.9, and 61\%, respectively) [42]. Similarly, total AUDIT scores were slightly higher than those seen in previous studies of sportspeople in New Zealand (mean=12.5) [8], however, it should be noted that the absence of a sampling frame and non-random selection makes comparison problematic. Similarly, differences in drinking outcomes between men and women were small (see Table 1), which suggests that the sporting culture is particularly detrimental to women's drinking. There is vigorous debate in several countries over the need for bans on alcohol advertising and sponsorship, with calls for more evidence to inform these debates [22-26]. The present study provides some evidence from the UK, showing that alcohol industry sponsorship is possibly harmful. Taken together with recent longitudinal research showing that indirect exposure to alcohol sponsorship in sport is associated with the later development of drinking expectancies and 
behaviour [30], and the high levels of hazardous drinking in sport, health policy makers and sports administrators should consider whether the harms outweigh the financial benefits of alcohol sponsorship.

The tobacco industry has been prohibited from advertising during sports broadcasts and from sponsoring sport in many countries and there is no evidence to suggest that this has resulted in a decline in sport participation or performance. Similar action has been called for in regard to the alcohol industry [27], with emphasis on the application on a precautionary principle, in particular, on shifting the burden of proof to the proponents of the potentially harmful activity, i.e., the alcohol industry. Secondly, in absence of strong evidence of causation which may take many years to develop, public health authorities are compelled to take preventive action [27].

An objection raised by some parties, including sporting organisations, is that industry funds are crucial for the survival of sporting activity. In the same way that hypothecated tobacco taxes have been used in some countries to fund health programs and elite and community-level sport, tax revenues from alcohol could be employed to fund sport. There would be value in further examining the association between alcohol industry sponsorship and later alcohol use in sports participants with prospective measurement of exposure, and of investigating mechanisms by which this exposure increases the risk of hazardous drinking.

\section{Acknowledgements}

The research was supported by a grant from Alcohol Research UK. KOB was also supported by funding from the Australian Research Council, VicHealth, Australian National Preventive Health Agency, and the Australian Drug Foundation. KK's contribution to the research was funded by a Senior Research Fellowship from the National Health \& Medical Research Council. 


\section{References}

1. Rehm J., Mathers C., Povova S., Thavorncharoensap M., Teerawattananon Y., Patra J. Global burden of disease and injury and economic cost attributable to alcohol use and alcohol-use disorders. Lancet 2009; 373: 2223-33.

2. Nutt D. J., King L. A., Phillips L. D. Drug harms in the UK: a multicriteria decision analysis. Lancet 2010; 376: 1558-1565.

3. Strategy Unit. Alcohol Harm Reduction Strategy for England. London: Prime Minister's Strategy Unit, UK, 2004.

4. Gill J. S. Reported levels of alcohol consumption and binge drinking within the UK undergraduate student population over the last 25 years. Alcohol Alcohol 2002; 37: 109-120.

5. Kuo M., Adlaf E. M., Lee H. et al. More Canadian students drink but American students drink more: comparing college alcohol use in two countries. Addiction 2002; 97: 1583-1592.

6. Nelson T.F., Wechsler H. Alcohol and college athletes. Med Sci Sports Exerc 2001; 33: 43-47.

7. Martens M. P., Dams-O’Connor K., Beck N.C. A systematic review of college student-athlete drinking: Prevalence rates, sport-related explanations, and interventions. J Substance Abuse Treatment 2006; 31: 305-316.

8. O’Brien K.S., Blackie J., Hunter J.A. Hazardous drinking in elite New Zealand sportspeople. Alcohol Alcohol 2005; 40: 239-41.

9. O’Brien K.S., Kolt G., Webber A., Hunter J.A. Alcohol consumption in sport: The influence of sporting idols, friends and normative drinking practices. Drug Alcohol Rev 2010; 29: 676-683.

10. Wechsler H., Davenport A.E., Dowdall G.W., Grossman S.J., Zanakos S.I. Binge drinking, tobacco, and illicit drug use and involvement in college athletics. J Am Col Health 1997; 45: 195-200.

11. Leichliter J.S., Meilman P.W., Presley C.A., Cashin J.R. Alcohol use and related consequences among students with varying levels of involvement with college athletics. J Am Col Health 1998; 46, 257-262. 
12. Partington S., Partington E., Heather N., et al. The relationship between membership of a university sports group and drinking behaviour among students at English Universities. Addiction Res Theory 2013; 24: 339-347.

13. O’Brien K.S., Kolt G., Webber A., Hunter J.A. Alcohol consumption in sport: The influence of sporting idols, friends and normative drinking practices. Drug Alc Review 2010; 29: 676-683.

14. Collins T., Vamplew W. Mud, Sweat and Beers: A Cultural History of Sport and Alcohol. New York: Berg; 2002.

15. Center on Alcohol Marketing and Youth (2004). Alcohol Advertising on Sports Television 2001 to 2003. http://camy.org/factsheets/pdf/AlcoholAdvertisingSportsTelevision20012003.pdf

16. Lefton T. (31 August 2009). A-B shifts approach to sports ties. http://www.sportsbusinessjournal.com/article/63394

17. Babor T., Caetano R., Casswell S., Edwards G., Giesbrecht N., Graham K. et al. Alcohol: No Ordinary Commodity, 2nd ed. London: Oxford University Press; 2010.

18. Casswell S., Thamarangsi T. Reducing harm from alcohol: call to action. Lancet 2009; 373: $2247-57$.

19. Anderson P., Chisholm D., Fuhr D.C. Effectiveness and cost-effectiveness of policies and programmes to reduce the harm caused by alcohol. Lancet $2009 ; 373: 2234-46$.

20. Anderson P., De Bruijn A., Angus K., Gordon R., Hastings G. Impact of alcohol advertising and media exposure on adolescent alcohol use: a systematic review of longitudinal studies. Alcohol Alcohol 2009; 44: 229-43.

21. Smith L.A., Foxcroft D.R. The effect of alcohol advertising, marketing and portrayal on drinking behaviour in young people: systematic review of prospective cohort studies. BMC Pub Health 2009; 9: 51.

22. British Medical Association Board of Science. Under the Influence: the Damaging Effect of Alcohol Marketing on Young People. London: British Medical Association, 2009. 
23. Australian Medical Association. Alcohol Marketing and Young People: Time for a new policy agenda. Kingston, ACT. Australian Medical Association, 2012.

24. Irish Medical Organisation. Submission to the Oireachtas Joint Committee on Health and Children on Alcohol Marketing. November 2011.

25. House of Commons Health Select Committee. Alcohol: First report of session 2009-10, Volume 1, London. The Stationary Office, 2010.

26. The Government Response to the Health Select Committee Report on Alcohol. London. The Stationary Office, 2010.

27. Kypri K., O’Brien K., Miller P. Time for precautionary action on alcohol industry funding of sporting bodies. Addiction 2009; 104: 1949-1950.

28. O’Brien K.S., Kypri K. Alcohol industry sponsorship of sport and drinking levels in New Zealand sportspeople. Addiction 2008; 103: 1961-1966.

29. O’Brien K.S., Miller PG, Kolt G, Martens M, Webber A. Alcohol industry and non-alcohol industry sponsorship of sportspeople and drinking. Alcohol Alcohol 2011; 46: 210-213.

30. de Bruijn A., Tanghe J., Beccaria F., Buljaski M., Celata C., Gosselt, J. et al. Report on the impact of European alcohol marketing exposure on youth alcohol expectancies and youth drinking. Alcohol Measures for Public Health Research Alliance (AMPHORA), 2012.

31. Reilly J. (5 Sept 2010). Last orders on the cards for alcohol ads in sports: But most people oppose outright ban on drink firms' sponsorship. Sunday Independent. http://www.independent.ie/national-news/last-orders-on-the-cards-for-alcohol-ads-in-sports2325328.html

32. Ameratunga S.N., Norton R.N., MacMahon S.W., Smith G.S., Jackson R.T., Currie R., et al. A prospective cohort study of blood donors: methodological issues in the investigation of injuries and chronic diseases. ANZJPH 1998; 22: 578-82.

33. Tabachnick, B., \& Fidell, L. Using multivariate statistics. New York: Harper Jr Row; 2001. 
34. Saunders J.B., Aasland O.G., Babor T.F., de la Fuente J.R., Grant M. Development of the Alcohol Use Disorders Identification Test (AUDIT): World Health Organisation Collaborative Project on Early Detection of Persons with Harmful Alcohol Consumption-II. Addiction 1993; 88: 791-804.

35. Conigrave K.M., Saunders J.B., Reznik R.B. Predictive capacity of the AUDIT questionnaire for alcohol-related harm. Addiction 1995; 90: 1479-1485.

36. Oakes J.M. The (mis)estimation of neighborhood effects: causal inference for a practicable social epidemiology. Soc Sci Med 2004; 58: 1929-52.

37. Adams S., Blackburn M.L., Cotti C.D. Minimum wages and alcohol-related traffic fatalities among teens. Rev Econ Statistics 2012; 94: 828-840.

38. Corcoran S (24 $4^{\text {th }}$ June 2013). European association against alcohol sponsorship ban in Ireland. http://www.businessandleadership.com/marketing/item/41618-european-association/

39. Glendinning M., (27 Nov 2008). Alcohol sponsorship all clear, says drinks group. Sport Business. http://www.sportbusiness.com/britsport/168360/alcohol-sponsorship-all-clear-saysdrinks-group.

40. Martha C., Grélot L., Peretti-Watel P. Participants' sports characteristics related to heavy episodic drinking among French students. Int J Drug Polic 2009; 20: 152-160.

41. Martens M.P., Dams-O’Connor K,, Beck N.C. A systematic review of college student-athlete drinking: prevalence rates, sport-related explanations, and interventions. J Substance Abuse Treatment 2006; 31: 305-16.

42. Heather N., Partington S., Partington E., et al. Alcohol use disorders and hazardous drinking among undergraduates at English universities. Alcohol Alcohol 2011; 46: 270-277.. 
Table 1. Frequency and percentage of sports reported as being played by participants.

\begin{tabular}{|c|c|c|}
\hline Sport & Frequency* & Percent \\
\hline Football (Soccer) & 452 & 18.49 \\
\hline Rugby (Union and League) & 445 & 18.20 \\
\hline Hockey & 207 & 8.47 \\
\hline Cricket & 177 & 7.24 \\
\hline Netball & 163 & 6.67 \\
\hline Basketball & 124 & 5.07 \\
\hline Athletics & 114 & 4.66 \\
\hline Lacrosse & 95 & 3.89 \\
\hline Swimming & 79 & 3.23 \\
\hline Tennis & 52 & 2.13 \\
\hline Water polo & 50 & 2.04 \\
\hline Badminton & 49 & 2.00 \\
\hline Squash & 45 & 1.84 \\
\hline American football & 44 & 1.80 \\
\hline Volleyball & 43 & 1.76 \\
\hline Martial arts & 37 & 1.51 \\
\hline Rowing & 35 & 1.43 \\
\hline Dance Sport & 32 & 1.31 \\
\hline Body Building & 32 & 1.31 \\
\hline Golf & 28 & 1.15 \\
\hline Fencing & 19 & 0.78 \\
\hline Gymnastics & 17 & 0.70 \\
\hline Skiing & 16 & 0.65 \\
\hline Weight Lifting & 15 & 0.61 \\
\hline Trampoline & 13 & 0.53 \\
\hline Equestrian & 11 & 0.45 \\
\hline Cycling & 11 & 0.45 \\
\hline Boxing & 9 & 0.37 \\
\hline Cheer Leading & 9 & 0.37 \\
\hline Table Tennis & 7 & 0.29 \\
\hline Platform Diving & 5 & 0.20 \\
\hline Sailing & 4 & 0.16 \\
\hline Softball & 3 & 0.12 \\
\hline Ice Skating & 1 & 0.04 \\
\hline Lawn Bowls & 1 & 0.04 \\
\hline Australian Football & 1 & 0.04 \\
\hline
\end{tabular}

* Note: the total frequency of sports played is 2445 . This is due to some participants listing participation in multiple sports. 
Table 2. Characteristics of the sample. Numbers other than mean and standard deviation scores are representated as raw counts and percentages (\%). Significant sponsorship differences are indicated for age, disposable income, and all drinking behaviour scores.

\begin{tabular}{|c|c|c|c|}
\hline Characteristic & $\begin{array}{l}\text { No sponsorship } \\
\mathrm{n}=1473 \text { (72) }\end{array}$ & $\begin{array}{l}\text { Sponsorship } \\
\mathrm{n}=575(28)\end{array}$ & $\begin{array}{l}\text { Total } \\
\mathrm{n}=2048\end{array}$ \\
\hline \multicolumn{4}{|l|}{ Sex $* *$} \\
\hline Female & $614(69)$ & $278(31)$ & $892(44)$ \\
\hline Male & $858(74)$ & $297(26)$ & $1155(56)$ \\
\hline Mean age $* *$ & $20.05(1.87)$ & $19.77(1.50)$ & $19.97(1.78)$ \\
\hline Mean disposable income $£$ & $66.87(83.42)$ & $56.78(52.90)$ & $63.58(75.00)$ \\
\hline Mean alcohol consumption score $* * *$ & $7.86(2.81)$ & $8.58(2.39)$ & $8.05(2.72)$ \\
\hline Mean AUDIT total score $* * *$ & $13.97(7.15)$ & $15.74(6.90)$ & $14.47(7.12)$ \\
\hline Hazardous drinker (AUDIT $8+$ ) $* * *$ & $1212(70)$ & $512(30)$ & $1724(84)$ \\
\hline Alcohol dependence (AUDIT 16+) *** & $568(66)$ & $287(34)$ & $855(42)$ \\
\hline \multicolumn{4}{|l|}{ Location *** } \\
\hline North West & $640(63)$ & $374(37)$ & $1014(50)$ \\
\hline Midlands & $200(74)$ & $72(26)$ & $272(13)$ \\
\hline London & $201(85)$ & $36(15)$ & $237(11)$ \\
\hline Southern England & $432(82)$ & $93(18)$ & $525(26)$ \\
\hline Total & $1473(72)$ & $575(28)$ & $2048(100)$ \\
\hline \multicolumn{4}{|l|}{ Level of sponsorship } \\
\hline None & $1473(72)$ & & \\
\hline Team only & & $214(10)$ & \\
\hline Club only & & $195(10)$ & \\
\hline Team and Club only & & $144(7)$ & \\
\hline Personal combinations & & $22(1)$ & \\
\hline
\end{tabular}

*Significant sponsorship difference at the $P<0.05$ level, $* *$ Significant at the $P<0.01$ level. ***Significant at the $P<$ 0.001 level. Total (\%) are with respect to the whole sample. 
Table 3. Bivariate and multivariable regression analysis of alcohol consumption score after accounting for covariates.

\begin{tabular}{|c|c|c|c|}
\hline \multirow[b]{2}{*}{ Parameters $^{\mathrm{a}}$} & \multicolumn{3}{|c|}{ Alcohol Consumption } \\
\hline & Unadjusted $\beta \quad(95 \% \mathrm{CI})$ & \multicolumn{2}{|c|}{ Adjusted $\beta^{\mathrm{b}} \quad(95 \% \mathrm{CI})$} \\
\hline Age & $-0.16 \quad(-0.22,-0.09)^{* * *}$ & -0.15 & $(-0.22,-0.08) * * * *$ \\
\hline Male (Reference: Females) & $(0.19,0.96)^{* *}$ & 0.38 & $(-0.13,0.89)$ \\
\hline \multicolumn{4}{|c|}{ Weekly disposable income (Reference: $£ 0-20$ ) } \\
\hline$£ 21-40$ & $(0.09,1.37)^{* *}$ & 0.74 & $(0.23,1.25)^{* *}$ \\
\hline$£ 41-60$ & $(0.67,1.53)^{* * *}$ & 1.09 & $(0.71,1.46)^{* * * *}$ \\
\hline$£ 61-80$ & $(0.76,1.64) * * *$ & 1.12 & $(0.80,1.45)^{* * * *}$ \\
\hline$£ 81-100$ & $(0.54,1.68) * *$ & 1.14 & $(0.67,1.60)^{* * * *}$ \\
\hline$>£ 100$ & $(0.13,1.08)^{*}$ & 0.63 & $(0.18,1.09) * *$ \\
\hline \multicolumn{4}{|l|}{ Location (Reference: London) } \\
\hline North West & $(0.82,2.22) * * *$ & 1.24 & $(0.48,2.00)^{* *}$ \\
\hline Midlands & $(-0.22,1.20)$ & 0.37 & $(-0.29,1.02)$ \\
\hline Southern England & $(0.51,1.94) * * *$ & 1.12 & $(0.42,1.83) * *$ \\
\hline \multicolumn{4}{|c|}{ Sponsorship (Reference: No alcohol sponsorship=0) } \\
\hline Team & $(027,0.98)^{* *}$ & 0.41 & $(0.07,0.75)^{*}$ \\
\hline Club & $(0.44,1.56)^{* * *}$ & 0.73 & $(0.12,1.34)^{*}$ \\
\hline Team and club & $(0.40,1.15) * * *$ & 0.79 & $(0.28,1.29)^{* *}$ \\
\hline Personal combinations & $(0.42,2.14) *$ & 1.27 & $(0.42,2.11)^{* *}$ \\
\hline
\end{tabular}

*Significant at the $P<0.05$ level, **Significant at the $P<0.01$ level. ***Significant at the $P<0.001$ level.

${ }^{\text {a} L e v e l ~ o f ~ s p o n s o r s h i p ~ c a t e g o r i e s ~ a r e ~ m u t u a l l y ~ e x c l u s i v e, ~ a n d ~ a r e ~ l i m i t e d ~ t o ~ t h o s e ~ w i t h ~ s u f f i c i e n t ~ n u m b e r s ~ t o ~ p e r m i t ~ v a l i d ~ s t a t i s t i c a l ~ i n f e r e n c e . ~ A U D I T: ~ A l c o h o l ~ U s e ~ D i s o r d e r s ~}$ Identification Test; CI: confidence interval. ${ }^{b}$ Linktest suggests that the overall model was correctly specified ( $\left.\mathrm{t}=-0.06 ; \mathrm{p}>0.45\right)$; testing for multicollinearity was not possible due to bootstrapping the model. 
Table 4. Bivariate and multivariable logistic regression analysis for hazardous drinking and alcohol dependence after accounting for covariates.

\begin{tabular}{|c|c|c|}
\hline \multirow[b]{2}{*}{ Parameters $^{\mathrm{a}}$} & \multicolumn{2}{|c|}{ Hazardous drinking (AUDIT Total 8+) } \\
\hline & OR $(95 \% \mathrm{CI})$ & Adjusted $\mathrm{OR}^{\mathrm{b}, \mathrm{c}}(95 \% \mathrm{CI})$ \\
\hline Age & $0.92(0.87,0.97)^{* *}$ & $0.92(0.88,0.97)^{* *}$ \\
\hline $\begin{array}{l}\text { Male (Females as } \\
\text { reference) }\end{array}$ & $1.29(0.77,2.15)$ & $1.26(0.78,2.01)$ \\
\hline \multicolumn{3}{|c|}{ Weekly disposable income (Reference: $£ 0-20$ ) } \\
\hline$£ 21-40$ & $1.92(1.18,3.14)^{* *}$ & $2.03(1.33,3.10)^{* *}$ \\
\hline$£ 41-60$ & $2.31(1.57,3.37)^{* * * *}$ & $2.40(1.66,3.45)^{* * * *}$ \\
\hline$£ 61-80$ & $3.03(1.62,5.68)^{* * *}$ & $2.96(1.71,5.11)^{* * *}$ \\
\hline$£ 81-100$ & $2.12(1.30,3.46)^{* *}$ & $2.28(1.38,3.76)^{* *}$ \\
\hline$>£ 100$ & $1.67(1.14,2.42)^{* *}$ & $1.70(1.13,2.58)^{*}$ \\
\hline \multicolumn{3}{|c|}{ Location (Reference: London=0) } \\
\hline North West & $3.28(1.93,5.59)^{* * * *}$ & $2.78(1.73,4.45)^{* * * *}$ \\
\hline Midlands & $1.52(0.93,2.50)$ & $1.41(0.91,2.20)$ \\
\hline Southern England & $2.60(1.66,4.06)^{* * * *}$ & $2.55(1.65,3.95)^{* * * *}$ \\
\hline \multicolumn{3}{|c|}{ Sponsorship (Reference: No alcohol sponsorship=0) } \\
\hline Team & $1.50(0.97,2.30)$ & $1.25(0.82,1.91)$ \\
\hline Club & $2.21(1.14,4.28)^{*}$ & $1.78(0.87,3.63)$ \\
\hline Team and club & $1.94(1.18,3.17)^{* *}$ & $2.04(1.04,4.00)^{*}$ \\
\hline Personal combinations & $4.30(1.42,13.01)^{* *}$ & $4.12(1.29,13.15)^{*}$ \\
\hline
\end{tabular}

*Significant at the $P<0.05$ level.**Significant at the $P<0.01$ level. ***Significant at the $P<0.001$ level. ${ }^{a}$ Level of sponsorship categories are mutually exclusive, and are limited to those with sufficient numbers to permit valid statistical inference. AUDIT: Alcohol Use Disorders Identification Test; CI: confidence interval. ${ }^{\mathrm{b}}$ Hosmer-Lemeshow tests also indicated a good fit for models (hazardous drinking, $\chi 2=5.29, \mathrm{p}>.73$; and alcohol dependence, $\chi 2=15.22 \mathrm{p}=.056$ ). ${ }^{\circ}$ Linktest suggests that the overall model was correctly specified (hazardous drinking $\mathrm{t}=-0.03 ; \mathrm{p}>0.82$; alcohol dependence $\mathrm{t}=0.08 ; \mathrm{p}>0.55$ ). 